\title{
TYPICAL OPHTHALMOSCOPIC PICTURE OF "CHERRY-RED SPOT" IN AN ADULT WITH THE MYOCLONIC SYNDROME*
}

BY

\author{
R. TITTARELLI, $\dagger$ M. GIAGHEDDU, AND V. SPADETTA
}

From the Departments of Ophthalmology and Neurology, University Hospitals, Cagliari, Sardinia, Italy

THE typical ophthalmoscopic picture of a "cherry-red spot" is only one of the pathognomonic elements of infantile amaurotic idiocy, or Tay-Sachs' lipoidotic ganglioside disease (Danis, Bégaux, and Decock, 1957). A similar picture was also observed in Niemann-Pick disease (sphingomyelin lipoidosis disease) in about 60 per cent. of cases (Videbaek, 1949) and even in two cases of Gaucher's cerebrosidic lipoidosis disease (Eyb, 1952; Tyler, 1957). The sphingolipoidosis now mentioned (van Bogaert, 1962) is typical of infancy, although even in adults rare cases of Niemann-Pick and Gaucher's diseases have been reported (Rutishauer, 1942; Dusendschon, 1946; Pfändler, 1946; Tyler, 1957).

As far as so-called "amaurotic idiocy" is concerned it is well known that other forms are present as well as the infantile type, which chronologically may be classified as follows:

(1) Congenital (Normann and Wood).

(2) Infantile (Jansky-Bielschowsky).

(3) Juvenile (Vogt-Spielmeyer; Batten-Mayou).

(4) Adult (Kufs).

(5) Pre-senile (van Bogaert and Borremans).

The typical cherry-red spot, however, is present only in the Tay-Sachs' infantile type, while in the other forms the most varied fundus pictures may be observed, from atrophy of the optic nerve alone to macular changes and tapeto-retinal degeneration, with or without atrophy. In the adult and pre-senile types fundus changes are quite exceptional.

The ophthalmoscopic finding of a typical cherry-red spot in an adult is by itself very rare indeed, but the clinical report becomes even more interesting if a particular neurological picture is found at the same time. Such a case is reported here.

\section{Case Report}

A farmer, aged 24, was admitted to the Neurological Department of the University of Cagliari in November, 1962. No pathological signs in the familial and personal remote histories were recorded, apart from the fact that about ten years previously the patient had consulted an ophthalmologist for undefined eye troubles. His physiological history was completely normal.

The symptoms which led to his admission to hospital had started about four years previously with a sensation of decrease of strength in the lower limbs, subsequently associated with a progressive

* Received for publication February 15, 1965.

+ Present address: Clinica Oculistica Universitaria, Pisa, Italy. 
impairment of involuntary movements, emphasized by emotion and triggered off by stimuli of different kinds. In connexion with such movements the patient experienced a peculiar sensation "as if his body were crossed by electric current". These symptoms were gradually getting worse and the patient was compelled to give up his normal work. Ultimately, he was unable to leave his bed, to dress or feed himself, or to carry out any useful action because of the dramatic outbreak of hyperkinesis, which occurred with sudden and violent muscular spasms, affecting both the limbs and face muscles in a rather symmetrical and synchronous fashion. When appearing in the limbs, both agonists and antagonists were simultaneously affected; the onset stage occurred with three or four shocks and gave rise to a remarkable motor effect, which vanished in a short series of rapid oscillations of the segment affected. These hyperkineses, sometimes noticeable even at rest, were induced and exacerbated by widely different affective and sensory stimuli, namely, attention, emotion, and any other voluntary activity. As far as the latter was concerned, the intensity and frequency of the shocks increased as soon as the patient moved from a maintained posture to execute a simple or complicated movement. Consequently, writing became impossible and speech was severely impaired by the frequent contractions of the perioral, lingual, and laryngo-pharyngeal muscles. Apart from this dyskinesia the neurological examination did not reveal any other particular symptom.

From the psychic point of view no abnormalities, even on mental tests, were observed.

Electromyography (biceps and triceps brachii muscles) revealed the following: absence of activity at rest, brisk activity on insertion, normal recruitment.

Hyperkineses were electromyographically expressed by high-voltage bursts, highly rhythmic and perfectly synchronized in the two derivations (Fig. 1). Electromyographical examination was carried out by means of surface electrodes and recorded on paper in order to obtain quantitative information on the global activity of the two muscles. In this way it was possible to show the perfect synchrony of action potentials deriving from a pair of antagonists.

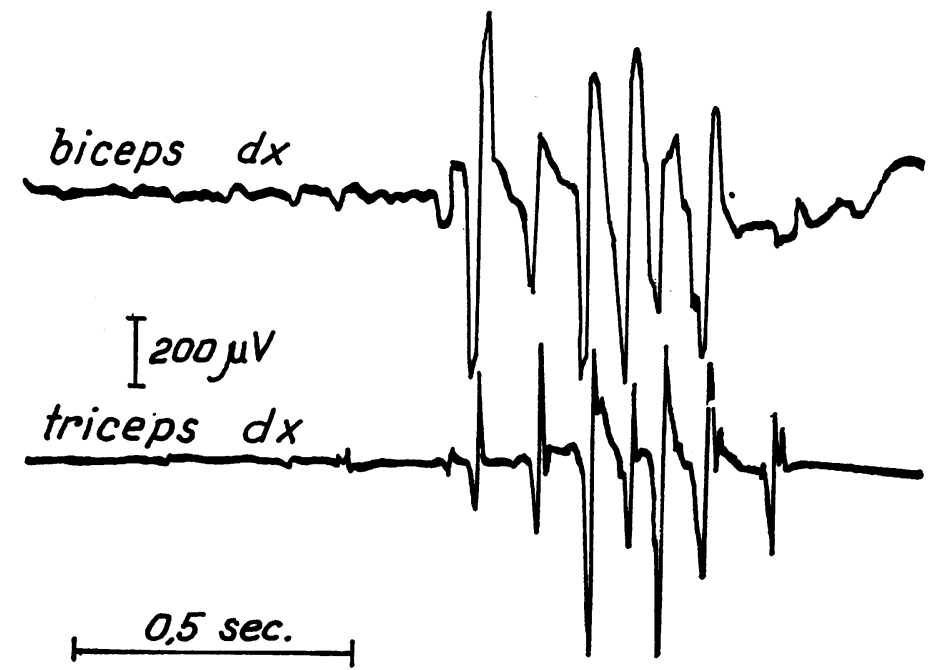

Fig. 1.-Electromyograph from biceps and triceps brachii muscles.

The routine electro-encephalogram and those with Megimide activation gave findings within the normal limits. Even the pneumo-encephalographic examination was normal.

The patient was sent to the Department of Ophthalmology of the University of Cagliari for examination.

His early history revealed that he had been previously examined twice, at 12 and 14 years of age, in another Eye Department, where an oblique mixed astigmatism was noted, with corrected vision of 10/10 in both eyes. Nothing abnormal was found at that time in the ocular fundus.

The patient reported that for about three years he had observed a slight progressive decrease of visual acuity in both eyes. The ophthalmological examination showed the corrected visual acuity to be $8 / 10$ for distance and second print for near vision in both eyes. The papillae of the 
ocular fundus (of both eyes) appeared to be pink coloured, slightly pale at the temporal edge, sharply bordered, and not elevated above the surrounding retinal surface. A wide physiological pit revealed the retinal vessels, which did not show any changes in their course and calibre and were normally distributed over the retinal surface. In the perimacular region a slight horizontally oval spot was noticed, two papillary diameters in size, grey coloured, sharply bordered, particularly thickened around the macula. The latter stood out clearly at the centre like a small wine-redcoloured spot (Fig. 2). No other ophthalmoscopic changes were appreciable.
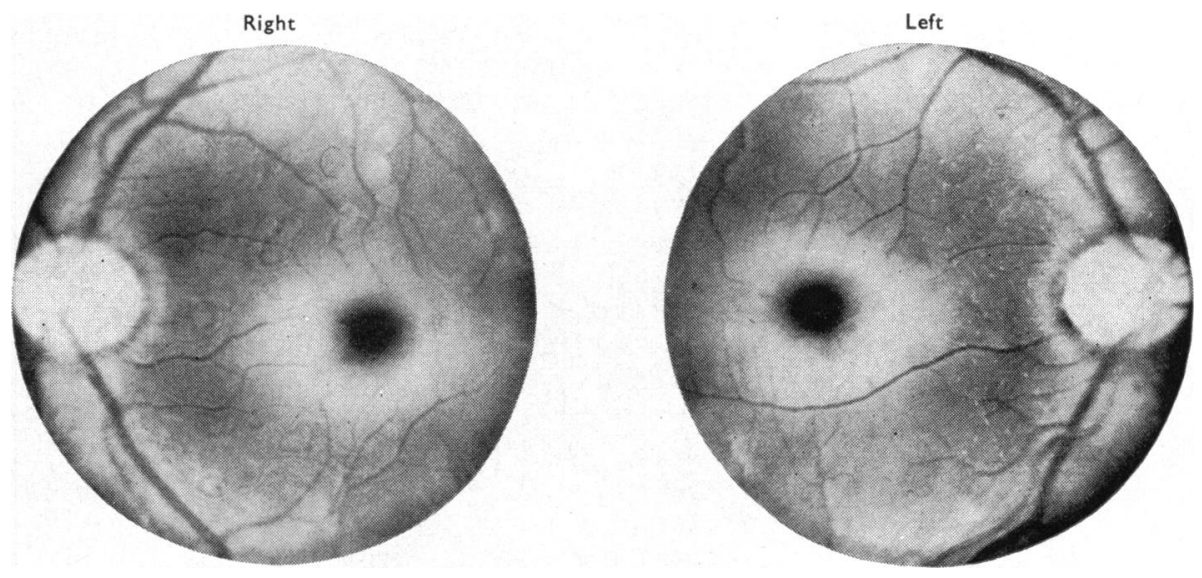

Fig. 2.-Fundus appearances.

Light sense was found to be normal, while perimetry revealed a tendency to a wide paracentral ring scotoma, which could best be defined by examination with the tangent screen (Fig. 3, opposite).

The electroretinogram was present and normal in both eyes (Fig. 4). The regularly shaped ocular globes and the adnexae appeared normal. Intra-ocular pressure and arterial retinal blood pressure were normal.
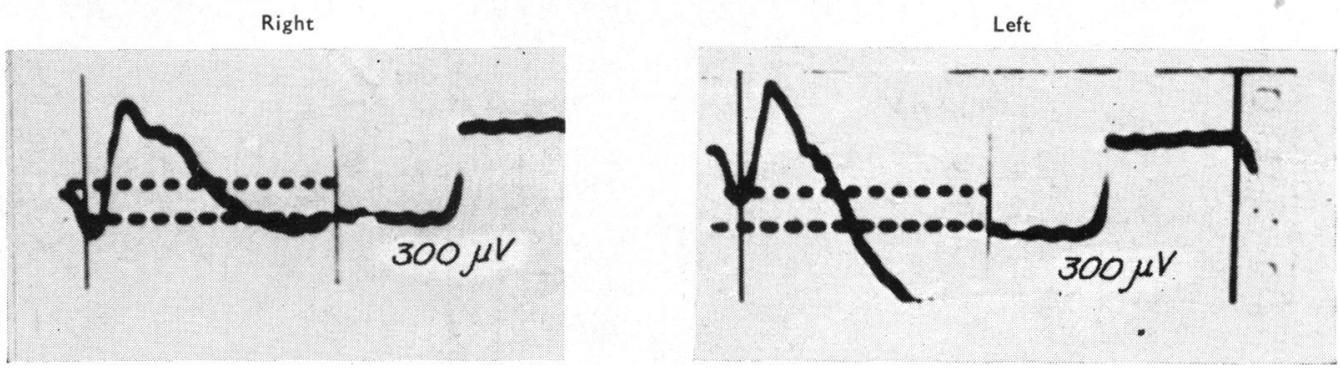

FIG. 4.-Electroretinogram. (The E.R.G. is recorded with Burian-Allen electrode. Amplifier time-constant, $1 \mathrm{sec}$. Time-marking, $50 \mathrm{c} / \mathrm{s}$. Stimulus energy, $0 \cdot 3$ joules, duration, $50 \mu \mathrm{sec}$. Full dark-adaptation.)

Internal examination did not reveal any pathological sign. Radiographic examination of the skull, long bones, pelvis, and spinal column was negative. During the three months spent in the clinic the symptoms remained quiet, stationary, and almost insensitive to various therapeutic treatments.

\section{Clinical Remarks}

The present report concerns an adult patient with neurological symptoms, characterized by involuntary movements associated with the well-known ophthalmoscopic picture of the "cherry-red spot". If the fundus picture obviously draws attention 

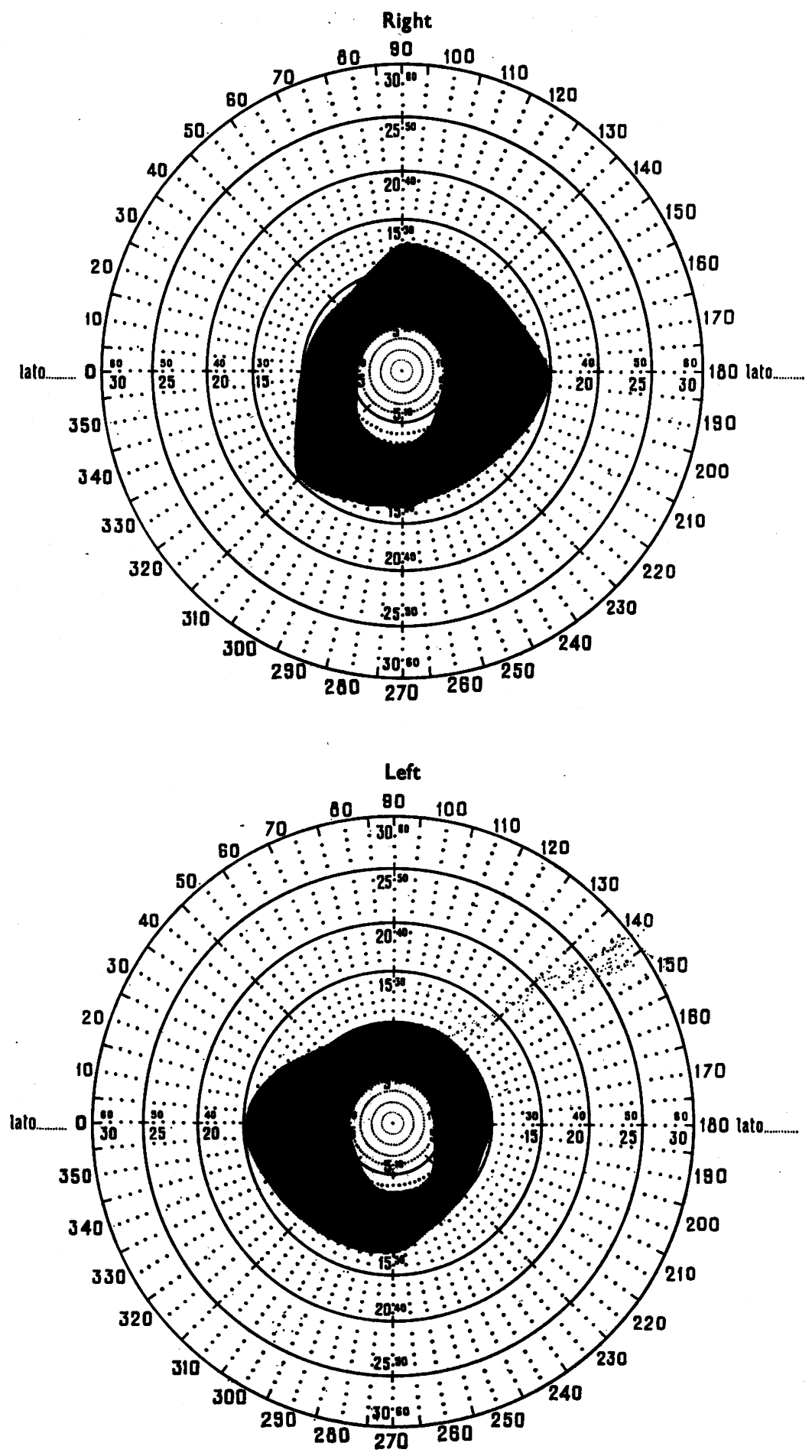

FIG. 3.-Visual fields (Goldmann perimeter). 
to glycosphingosidic lipoidosis and consequently to Tay-Sachs', Niemann-Pick, and Gaucher's diseases, the situation is quite different from the neurological aspect. From this point of view the hyperkinesia of which the patient complained may well be defined as a myoclonus. In favour of this assumption are the synchronous and symmetrical appearance of the phenomenon and the simultaneous involvement, clinically and electromyographically, of both agonist and antagonist muscles.

Electromyography clearly proved the perfect synchrony of the action potentials arising from the pair of antagonists.

The problem is still open to question, however, from the nosographic point of view. Myoclonic manifestations actually appear in several neurological affections, which we will survey briefly.

It seems apparent that the neurological syndrome we have observed cannot be confused with other myoclonic diseases. Our case is quite different from myoclonic encephalitis, lacking the phenomena of general involvement, the E.E.G. picture and the typically chronic course of the disease. We can rule out Friedrich's multiple paramyoclonia because in this case the muscle contractions of high frequency, without motor effect, only appear at rest. Even cerebellar myoclonic dyssynergia is to be discarded because of the absence of phenomena of cerebellar deficiency and also Unverricht-Lundborg's myoclonic epilepsy because of the absence of convulsive manifestations, of typical E.E.G. anomalies and psychic deterioration, and, finally, because of the adult age of the patient and the negative family history.

On a purely neurological background our case may therefore be considered as a myoclonic syndrome similar to those described by Gibbs and Gibbs (1950), Hänel and Bielschowsky (1915), Precechtel (1927), and D'Arrigo, Ferrari, and Spadetta (1962).

In all these cases, however, alterations of the fundus were missing. The only two cases similar to our own that we could find in the literature are those described by Anderson, Margolis, and Lynn (1958); these were two sisters, aged 17 and 19 years respectively, who both presented a typical cherry-red spot associated with a hyperkinesia, not classified by the authors, but probably to be considered, from their description, as a myoclonus.

\section{Discussion}

Because of the association of the ophthalmological and neurological signs reported we believe that our case may be classified with the so-called cerebro-retinal degenerations, which, because of the presence of the typical cherry-red spot must necessarily be restricted to the lipoidoses, particularly glycosphingosidic lipoidosis.

Among these forms, amaurotic idiocy and Niemann-Pick disease are to be emphasized, and for practical reasons we like to consider them separately, even if the most recent view of Franceschetti, Klein, Forni, and Babel (1951); Franceschetti, Klein, and Babel (1955); Franceschetti, Wildi, and Klein (1955); and van Bogaert and Klein (1955), on the basis of ophthalmoscopic and genetic correlations, is to fuse the two forms as variable manifestations of one fundamental metabolic disorder.

In the absence of the characteristic humoral changes and of those involving other organs (liver, spleen, glands, and reticulo-endothelial system), we believe that Niemann-Pick and Gaucher's disease may be rejected. Consequently, our case, 
even if lacking psychic alterations, should be classified with those of amaurotic idiocy.

In this respect it seems fitting to recall once more that these present under different forms, each one characterized by a proper age of onset. As we pass from the infantile to the adult and pre-senile forms, we see that the course becomes longer and the ophthalmoscopic signs more scanty and far from specific, until in the late forms the observation of fundus alterations becomes exceptional.

Villani (1933) described three brothers, aged 9, 7, and $1 \frac{1}{2}$ years, who were affected by amaurotic idiocy with retinal cherry-red spot and corneal degeneration. Recently, Villani (1964) reported that the patients died at the ages of 32, 25, and 20 years.

Cobb (1964) tells us that for many years he has been watching a girl who had cherry-red spots when she was about 2 years old and still has them at the age of nearly 30 , having very slowly deteriorated, with myoclonus, over the whole of this period. In accordance with Cobb's opinion we believe that these cases may stress the possibility of another variant of this syndrome.

In our case, where the disease started in adult life in association with neurological manifestations, the typical ophthalmoscopic picture of cherry-red spot was present. Such an occurrence is extremely rare.

Apart from the infantile forms the literature reveals only seven young subjects with such an ophthalmoscopic finding (Pesme and Verger, 1946; Wyburn-Mason, 1943; Anderson and others, 1958; Tyler, 1957; Smith, 1957). If the diagnosis of gangliosidic lipoid cerebro-retinal degeneration is maintained it remains only to inquire whether our case represents a mere symptomatological rarity or whether, in association with the cases already known, it constitutes a particular picture, whereby familial amaurotic idiocy may appear in late youth.

In this respect the absence of psychic alterations, typical of our own and of other cases, may be explained by the trend of the disease towards a characteristic progressive spread of symptoms.

\section{Summary}

A case is reported of a myoclonic syndrome in an adult male with the typical fundus picture of Tay-Sachs' disease.

Although there were no psychic disorders the authors believe that the case may be included in the group of amaurotic idiocies.

The rarity of this finding is stressed by the fact that 7 cases only of typical "cherry-red spot" have previously been described in young subjects. It is suggested that such cases represent a particular variant in which amaurotic idiocy is characterized by a late onset.

Dr. W. Cobb (National Hospital, London) has been kind enough to revise the manuscript.

\section{REFERENCES}

Anderson, B., Margolis, G., and Lynn, W. S. (1958). Amer. J. Ophthal., 45, No. 4, pt. II, p. 23.

Bogaert, L. van (1962). Rev. méd. Liège, 17, 273. and KLEIN, D. (1955). J. Génét. hum., 4, 23.

Coвb, W. (1964). Personal communication.

Danis, P., Bégaux, C., and Decock, G. (1957). J. Génét. hum., 6, 91. 
D'Arrigo, B., Ferrari, E., and Spadetta, V. (1962). Acta neurol. (Napoli), 17, 492.

Dusendschon, A. (1946). Quoted by Franceschetti, Klein, and Babel (1955).

EYB (1952). Quoted by Franceschetti, Klein, and Babel (1955).

FORD, F. R. (1960). "Diseases of the Nervous System in Infancy, Childhood and Adolescence", 4th ed., p. 817. Thomas, Springfield, Ill.

Franceschetti, A., Klein, D., and Babel, J. (1955). Arch. Neuro-psiquiat. (S. Paulo), 13, 69.

- , FoRNI, S., and BABEL, J. (1951). XVI Concilium ophthalmologicum, 1950, Britannia Acta, vol. 1, p. 157. , Wildi, E., and Klein, D. (1955). Acta genet. (Basel), 5, 343.

GibBs, F. A., and GiBBS, E. L. (1950). "Atlas of Electroencephalography", 2nd ed., vol. 1, AddisonWesley, Cambridge, Massachussets.

HÄNel, H., and BielsCHOWSKy, M. (1915). J. Psychol. neurol. (Lpz.), 21, 385.

Pesme, P., and Verger, P. (1946). Bull. Soc. franc. Ophtal., 59, 56.

PFÄNDLER, U. (1946). Schweiz. med. Wschr., 76, 1128.

Precechtel, A. (1977). Psychiat. neurol. Bladen, $31,147$.

RUTISHAUER, E. (1942). Schweiz. med. Wschr., 72, 677.

SMITH, J. L. (1957). Quoted by Walsh (1957).

TYLER, R. H. (1957). Quoted by Walsh (1957) and Ford (1960).

VIDEBAEK, A. (1949). Acta paediat. (Uppsala), 37, 95.

Villani, G. (1933). Boll. ocul., 12, 1328. (1964). Personal communication.

WaLSH, F. B. (1957). “Clinical Neuro-ophthalmology”, 2nd ed., p. 667. Williams and Wilkins, Baltimore. Wyburn-Mason, R. (1943). Brit. J. Ophthal., 27, 145, 193. 